\title{
İç mekânda kullanılan UV sistem parke verniği uygulanmış kayısı odununda yapay yaşlandırma performansının belirlenmesi
}

\author{
Ümit Ayata ${ }^{1 *}$ (i), Nevzat Çakıcıer² (i), Levent Gürleyen ${ }^{3}$ (D)
}

\section{$\ddot{\mathbf{O} z}$}

Kayısı ağacı meyvesi için bol miktarda yetiştirilmektedir. Kayısı odunu farklı amaçlarla kullanılmaktadır. Bu çalışmanın amacı, kayısı (Prunus armeniaca L.) odununa uygulanmış ultraviyole (UV) sistem parke vernikli katmanların yapay yaşlandırma karşısındaki performansını belirlemektir. Bu amaç ile kayısı odunu yüzeylerine endüstriyel uygulamalara uygun olarak 3 ve 5 kat olacak şekilde UV sistem parke verniği uygulanmıştır. Elde edilen malzemeler, UVA-340 lambalı hızlandırılmış bir yaşlandırma cihazında 252 ve 504 saat süreyle maruz bırakılmıştır. Daha sonra, yaşlandırma sonrası 1şıklılık $\left(L^{*}\right), \operatorname{kırmızı}\left(a^{*}\right)$ renk tonu, sarı $\left(b^{*}\right)$ renk tonu, $20^{\circ}, 60^{\circ}$ ve $85^{\circ}$ de liflere dik $(\perp)$ ve paralel $(/ /)$ parlaklık değerleri, yapışma direnci ve sarkaç sertliği (könig yöntemi) testleri belirlenmiştir. Araştırma sonuçlarına göre, bütün testler için varyans analizler anlamlı olarak elde edilmiştir. Yaşlandırmadan sonra her iki vernik uygulaması için, bütün parlaklık değerleri, sarı renk tonu ve 1şıklılık değerleri azalırken, kırmızı renk tonu değerleri artmıştır. 3 katlı uygulamada sertlik azalırken yapışma direnci artmış olunup, 5 kat uygulama zit bir sonuç vermiştir.

Anahtar kelimeler: Kayısı odunu, yapay yaşlandırma, renk, parlaklık, salınımsal sertlik

\section{Determination of the artificial aging performance of the apricot wood applied with UV system parquet varnish used indoors}

\begin{abstract}
Abundantly grown for apricot tree fruit. Apricot wood is used for different purposes. The aim of this study is to determine the performance of the ultraviolet (UV) system parquet varnished layers against artificial aging applied to apricot (Prunus armeniaca L.) wood. For this purpose, UV system parquet varnish was applied on apricot wood surfaces in 3 and 5 layers in accordance with industrial applications. The materials obtained were exposed for 252 and $504 \mathrm{~h}$ in an accelerated aging device with UVA-340 lamp. After aging, lightness $\left(L^{*}\right)$, red $\left(a^{*}\right)$ color tone, yellow $\left(b^{*}\right)$ color tone, perpendicular $(\perp)$ and parallel $(/ /)$ glossiness values to the fibers at $20^{\circ}, 60^{\circ}$ and $85^{\circ}$, adhesion resistance and pendulum hardness (könig method) tests were determined. According to the results of the research, variance analysis was obtained significantly for all tests. After aging, for both varnish applications, all glossiness values, yellow color tone and lightness values decreased, while red color tone values increased. While the hardness decreased in the 3-layer application, the adhesion resistance was increased, and the 5-layer application gave an opposite result.
\end{abstract}

Keywords: Apricot wood, weathering aging, color, glossiness, pendulum hardness 


\section{Giriş}

Kayısı (Prunus armeniaca L.) Rosaceae ailesinin bir üyesidir. Zengin bir vitamin ve mineral kaynağı olan kayısı meyvesi, dünya çapında en tanıdık meyve ürünlerinden birisidir (Baytop, 1999). Kayısı, dünya çapında 1lıman ve subtropikal bölgelerde yetişmektedir (Anonim, 2002).

Literatüre bakıldığında, kayısı odununda; elastiklik oranı 50.37, lif çeper kalınlığı 3.19 $\mu \mathrm{m}$, lif lümen genişliği $5.69 \mu \mathrm{m}$, lif genişliği $12.08 \mu \mathrm{m}$, lif uzunluğu $0.69 \mathrm{~mm}$, rijidite katsayıs1 24.81, Keçeleşme oranı 55.09, Runkel oran1 0.99 (Gençer ve ark., 2018), hava kurusu yoğunluk değerleri $815 \mathrm{~kg} / \mathrm{m}^{3}$ (Ayata ve Bal, 2019) ve $788 \mathrm{~kg} / \mathrm{m}^{3}$ (Çavuş, 2020), çivi tutma direnci teğet yüzeyde $16.05 \mathrm{~N} / \mathrm{mm}^{2}$, radyal yüzeyde $21.07 \mathrm{~N} / \mathrm{mm}^{2}$, enine yüzeyde 21.83 $\mathrm{N} / \mathrm{mm}^{2}$ (Ayata ve Bal, 2019), dinamik eğilme (ş̧ok) direnci $2.32 \mathrm{kj} / \mathrm{m}^{2}$, eğilme direnci $81.88 .00 \mathrm{~N} / \mathrm{mm}^{2}$, eğilmede elastikiyet modülü $6569.00 \mathrm{~N} / \mathrm{mm}^{2}$, vida tutma kapasitesi radyal yönde $47.34 \mathrm{~N} / \mathrm{mm}^{2}$, teğet yönde $48.89 \mathrm{~N} / \mathrm{mm}^{2}$ ve boyuna yönde $44.38 \mathrm{~N} / \mathrm{mm}^{2}$ (Çavuş, 2020) olarak belirlenmiştir. Kayısı ağacına ait ahşap malzeme, odunu müzik aletleri yapımında, tornacılıkta, bıçak kulpları yapımında ve oymacılıkta kullanılmaktadır (URL 1).

UV vernikleri, UV radyasyonu altında polimerize olan ve sert bir film oluşturan reaktif reçineler içermektedir. Ana bileşenleri oligomerler, monomerler, prepolimerler ve foto başlatıcıları olmaktadır (Kipphan, 2001). Literatürde; gülibrişim (Albizia julibrissin) (Gürleyen, 2020), dişbudak (Fraxinus excelsior) (1s1l işlemli $212^{\circ} \mathrm{C}$ 'de 2 saat) (Ayata ve ark., 2017b), üvez (Sorbus L.) (Gürleyen ve ark., 2017b), ceviz (Juglans regia) Amerikan ceviz (Juglans nigra), kırmızı Amerikan meşesi (Quercus rubra), akçaağaç (Acer pseudoplatanus L.) (Ayata ve ark., 2018), meşe (Quercus petraea L.) (Gürleyen ve ark., 2019), sarıçam (Pinus sylvestris L.) (Gürleyen ve ark., 2017a), kestane (Castanea sativa Mill.), limba (Terminalia superba), iroko (Chlorophora excelsa), sapelli (Entandrphragma cylindrocum) (Ayata ve Çavuş, 2018), limon (Citrus limon (L.) Burm.) (Ayata, 2019), kayın (Fagus orientalis Lipsky.) (Ayata ve ark., 2017a), doussie (Afzelia africana) (Gürleyen, 2021), şeker akçaağacı (Acer saccharum) (Vardanyan ve ark., 2014) ve adi kızılağaç (Alnus glutinosa Gaertn L.) (Salca ve ark., 2016) odunu türlerine tek ve çift kat olacak şekilde UV sistem verniklerin uygulandığı görülmektedir. UV sistem verniklenmiş malzemeler üzerinde çeşitli testlerin (renk, parlaklık, yüzeye yapışma ve salınımsal sertlik) yapıldığı bildirilmiştir.

Literatürde kayısı odununa ait sınırlı sayıda bilimsel çalışma bulunmaktadır ve vernik uygulamaları konusunda yeterli bir çalışmaya rastlanmamıştır. Bu çalışmanın amacı; kayısı odunundan hazırlanmış yüzeylere endüstriyel uygulamalara uygun olarak 3 ve 5 kat UV sistem parke verniği uygulanması ve UVA-340 lambalarının bulunduğu bir hızlandırılmış yaşlandırma cihazında 252 ve 504 saat sürelerine maruz bırakılması sonrası çeşitli testlerle yapay yaşlandırma performansının araştırılmasıdır.

\section{Materyal ve Metot}

\subsection{Materyal}

Kayısı (Prunus armeniaca L.) odunu İzmir'de bulunan bir kereste satıcısından temin edilmiştir. Malzemeler lif kıvrıklığı sorunu olmayan, mantar ve böcek kusuru olmayan, ardaksız ve budaksız olacak şekilde rastgele seçim yöntem ile alınmıştır. 100 x 10 × $2 \mathrm{~cm}$ boyutlarında hazırlanmış 30 adet deney örneği biçme ve rendeleme işlemlerinden geçirildikten sonra iklimlendirme işlemleri yapılmıştır (TS 2471, 1976). 


\subsection{Metot}

\subsubsection{UV sistem parke verniklerinin uygulaması}

Bu çalışmada kayısı odununa (100 cm x $10 \mathrm{~cm}$ x 1,7 cm boyutlarında) KPS firması (Düzce, Türkiye) tarafından endüstriyel uygulamalara göre, UV vernikleri (3 ve 5 kat) uygulanmıştır. UV sistem parke üretim aşamaları (3 ve 5 kat) Çizelge 1'de verilmiştir. Uygulamada kullanılan kimyasallara ait özellikler Ayata (2019) tarafından yapılan çalışmada ayrıntılı olarak bildirilmiştir.

Çizelge 1. UV sistem parke verniği üretim aşamaları (3 ve 5 kat)

\begin{tabular}{|c|c|}
\hline 3 kat uygulaması & 5 kat uygulaması \\
\hline \multicolumn{2}{|c|}{ Kalibre zımpara uygulaması ( 80 ve 120 kum) } \\
\hline \multicolumn{2}{|c|}{ Şeffaf UV kürlenmeli hidro astar $(\mathrm{T} 8028-0000) 10 \mathrm{~g} / \mathrm{m}^{2}\left(70^{\circ} \mathrm{C}\right)$} \\
\hline $\begin{array}{l}\text { UV yüksek parlaklikta perde kaplama } \\
\text { (T9120-0900N1) } 8 \mathrm{~g} / \mathrm{m}^{2}\end{array}$ & $\begin{array}{l}\text { UV sseffaf kürleşen sizdırmazlık macunu } \\
(\mathrm{T} 9110-0000 \mathrm{H}) 20 \mathrm{~g} / \mathrm{m}^{2}\left(70^{\circ} \mathrm{C}\right)\end{array}$ \\
\hline $\begin{array}{l}\text { UV lamba kurutma uygulaması } \\
\left(177 \mathrm{~mJ} / \mathrm{cm}^{2}\right)(2 \text { defa })\end{array}$ & $\begin{array}{l}\text { UV şeffaf kürleşen sizdirmazlık macunu } \\
(\mathrm{T} 9110-0000) 10 \mathrm{~g} / \mathrm{m}^{2}\left(170^{\circ} \mathrm{C}\right)(2 \mathrm{defa})\end{array}$ \\
\hline \multicolumn{2}{|c|}{ Kalibre zımparalama işlemi (280 ve 320 kum) } \\
\hline \multicolumn{2}{|c|}{ Șeffaf mat UV yağı (T9115-0000) $\left(8 \mathrm{~g} / \mathrm{m}^{2}\right)$} \\
\hline \multicolumn{2}{|c|}{ UV lamba kurutma uygulaması $\left(71 \mathrm{~mJ} / \mathrm{cm}^{2}\right)$} \\
\hline \multicolumn{2}{|c|}{ Şeffaf mat UV yağ 1 (T9115-0000) $\left(8 \mathrm{~g} / \mathrm{m}^{2}\right)$} \\
\hline lamba kuru & $\left.14 \mathrm{~mJ} / \mathrm{cm}^{2}\right)(2$ defa $)$ \\
\hline
\end{tabular}

\subsubsection{Hızlandırılmış yaşlandırma uygulaması}

UV sistem parke verniğine (3 ve 5 kat) sahip test numuneleri, ISO 4892-3 (2016) standardına göre QUV weathering tester (Q-Lab, Westlake, OH, US) cihazında 0.67 1şık yoğunluğu, 15 dakika su spreyi, 8 saat UV 1 şık, $50{ }^{\circ} \mathrm{C}$ sicaklık ortamına sahip koşullarda, UVA 340 lambalarına 252 ve 504 saatleri süresince maruz bırakılmıştır.

\subsubsection{Parlaklık ölçümlerinin yapılması}

Yaşlandırılmış ve yaşlandırılmamış UV sistem parke vernikli test örneklerinin parlaklık değerleri ISO 2813 (1994) standardına göre, ETB-0833 model glossmeter cihazında (Vetus Electronic Technology Co., Ltd., CN) $20^{\circ}, 60^{\circ}$ ve $85^{\circ}$ de liflere paralel $(/ /)$ ve dik $(\perp)$ olacak şekilde yapılmıştır.

\subsubsection{Renk parametrelerinin belirlenmesi}

UV sistem verniklenmiş test örneklerin kırmızı renk $\left(a^{*}\right)$ tonu, sarı renk $\left(b^{*}\right)$ tonu ve 1şıklılık $\left(L^{*}\right)$ değerleri ASTM D2244-3 (2007) standardına göre, 5 örnek üzerinde CS-10 colorimeter (CHN Spec, Çin) marka renk cihazında [Ölçüm koşulları: CIE $10^{\circ}$ standart gözlemci; CIE D65 ışık kaynağı, Aydınlatma sistemi: 8/d (8\% dağınık aydınlatma)] ölçülmüş̧ür. CIELAB sisteminde, $L^{*}$ ekseni, 100'den (beyaz) sıfıra (siyah) kadar değişen açıklığ $1, a^{*}$ kırmızı (+) ila yeşil (-) tonu ve $b^{*}$ sarıdan (+) maviye (-) tonu ifade etmektedir (Ayata, 2019). $\Delta b^{*}, \Delta L^{*}, \Delta E^{*}$ ve $\Delta a^{*}$ değerleri aşağıdaki formüller ile hesaplanmıştır.

$$
\begin{aligned}
& \Delta a^{*}=a^{*} \mathrm{UV} \text { uygulanmıs ve yaşlandırılmıs }-a^{*} \mathrm{UV} \text { uygulanmıs ve yaşlandırılmamıs } \\
& \Delta L^{*}=L^{*} \mathrm{UV} \text { uygulanmıs ve yaşlandırılmıs }-L^{*} \mathrm{UV} \text { uygulanmış ve yaşlandırılmamış } \\
& \Delta b^{*}=b^{*} \mathrm{UV} \text { uygulanmış ve yaşlandırılmıs }-b^{*} \mathrm{UV} \text { uygulanmıs ve yaşlandırılmamıs } \\
& \Delta E^{*}=\left[\left(\Delta L^{*}\right)^{2}+\left(\Delta a^{*}\right)^{2}+\left(\Delta b^{*}\right)^{2}\right]^{1 / 2}
\end{aligned}
$$




\subsubsection{König metoduna göre salınımsal sertlik değerinin belirlenmesi}

ASTM D 4366-95 (1984)'e standardı doğrultusunda könig metoduna göre salınımsal sertlik testi yaşlandırılmış ve yaşlandırılmamış test örnekleri üzerinde belirlenmiştir. Sertlik cihazında HRC sertliğinde $63 \pm 3.3$ ve $5 \pm 0.0005 \mathrm{~mm}$ çapında iki adet bilye bulunmaktadır.

\subsubsection{Yüzeye yapışma direncinin belirlenmesi}

Vernikli numunelere ait yüzeye yapışma direnci değerleri PosiTest AT-A (automatic) pull-off Adhesion Tester (Defelsko ${ }^{\circledR}$ crop., S/N AT11802, USA) cihazında ASTM D 4541 (1995) standardına göre belirlenmiştir. Araştırmada, 404 plastik çelik marka (Çekmeköy/İstanbul) hızlı yapıştırıcı (reçine ve katalizör) kullanılmıştır. UV sistem vernik uygulanmış test örneklerine ait yüzeyler $20 \mathrm{~mm}$ olan çekme silindirleri normal oda sıcaklığında $\left(20^{\circ} \mathrm{C} \pm 2\right)$ yapıştırılmış olup, 24 saat süreyle kurumaya bırakılmıştır. Yapışma direnci 5 no'lu formül ile hesaplanmıştır.

$$
\mathrm{X}=\left[(4 \times \mathrm{F}) /\left(\pi \times \mathrm{d}^{2}\right)\right]
$$

Burada;

$\mathrm{X}$ : yapışma direnci $\left(\mathrm{N} / \mathrm{mm}^{2}\right)$,

F: kopma anındaki kuvvet (Newton)

$\mathrm{d}$ : çekme silindirinin çapını $(\mathrm{mm})$ ifade etmektedir.

\section{3. İstatistiksel analiz}

$\mathrm{Bu}$ çalışmada, bir SPSS programı yardımıyla homojenlik grupları, standart sapmalar, minimum ve maksimum değerler, ortalama ve varyans analizi belirlenmiştir. Toplamda 1170 adet (parlaklık $720+$ renk $360+$ salınımsal sertlik $60+$ yüzey yapışma direnci 30 ) ölçüm alınmıştır.

\section{Bulgular ve Tartışma}

Renk parametreleri için belirlenmiş olan varyans analizlerine ait sonuçlar Çizelge $2^{\text {‘de }}$ göstermiştir. Belirlenmiş olan bu verilere göre, $L^{*}, a^{*}$ ve $b^{*}$ parametreleri için vernik türü (A), yaşlandırma süresi $(B)$ ve etkileşim $(\mathrm{AB})$ anlamlı olarak elde edilmiştir.

Çizelge 2. Renk parametreleri için varyans analizlerine ait sonuçlar

\begin{tabular}{|c|c|c|c|c|c|c|}
\hline Test & Varyans Kaynağı & Kareler & Serbestlik & Ortalama & F değeri & $\alpha \leq 0,05$ \\
\hline \multirow{3}{*}{$L^{*}$} & Vernik Türü (A) & 139.623 & 1 & 139.623 & 236.923 & $0.000^{*}$ \\
\hline & Yaşlandırma Süresi (B) & 13242.449 & 2 & 6621.225 & 11235.414 & $0.000^{*}$ \\
\hline & Etkileşim (AB) & 75.477 & 2 & 37.739 & 64.038 & $0.000^{*}$ \\
\hline \multirow{3}{*}{$a^{*}$} & Vernik Türü (A) & 171.650 & 1 & 171.650 & 399.870 & $0.000^{*}$ \\
\hline & Yaşlandırma Süresi (B) & 4583.606 & 2 & 2291.803 & 5338.911 & $0.000^{*}$ \\
\hline & Etkileşim (AB) & 109.618 & 2 & 54.809 & 127.681 & $0.000^{*}$ \\
\hline \multirow{3}{*}{$b^{*}$} & Vernik Türü (A) & 17.526 & 1 & 17.526 & 43.580 & $0.000^{*}$ \\
\hline & Yaşlandırma Süresi (B) & 6110.828 & 2 & 3055.414 & 7597.411 & $0.000^{*}$ \\
\hline & Etkileşim (AB) & 54.138 & 2 & 27.069 & 67.308 & $0.000^{*}$ \\
\hline \multicolumn{7}{|c|}{$L^{*}$ : Işıklılık değeri, $a^{*}:$ Kırmızı renk tonu değeri, $b^{*}:$ Sarı renk tonu değeri, *: Anlamlı } \\
\hline
\end{tabular}


Renk parametreleri için SPSS sonuçları $\left(L^{*}, a^{*}\right.$ ve $\left.b^{*}\right)$ Çizelge 3'de verilmiştir. Çizelge 3'e göre, $L^{*}, a^{*}$ ve $b^{*}$ değerleri 3 ve 5 katmanlı UV sistem katmanlarına ait kontrol test örneklerinde çok benzer sonuçlara sahiptir. 3 ve 5 katmanlı uygulamalar için sırasıyla, $L^{*}=$ 58.06 ve $58.13, a^{*}=12.88$ ve 13.07 ve $b^{*}=30.72$ ve 31.22 olarak elde edilmiştir.

Buna benzer sonuçlar Gürleyen ve ark., (2017c) tarafından yapılan tek ve çift kat UV sistem vernik uygulamasına sahip odun türlerinde de elde edilmiştir. Yaşlandırmadan sonra her iki vernik türü için, $L^{*}$ ve $b^{*}$ tonu değerleri azalırken, $a^{*}$ tonu değerlerinin arttığ görülmüş olup, bu parametrelere ait artış ve azalış yüzdeleri Çizelge 3 'de verilmiştir. 252 saatlik yaşlandırma uygulaması sonunda her iki UV vernik uygulaması için $a^{*}$ tonu değerleri artmış, 504 saat sonunda hafif bir düşüş göstermiştir.

Söğütlü ve Sönmez (2006) tarafından $L^{*}$ değerindeki artışın görülmesi daha açık renk anlamı verdiği, azalışın görülmesi ise koyulaşması anlamına geldiği şeklinde bildirilmiştir.

Çizelge 3. Renk parametrelerine $\left(L^{*}, a^{*}\right.$ ve $\left.b^{*}\right)$ ait sonuçlar

\begin{tabular}{|c|c|c|c|c|c|c|c|c|c|c|}
\hline \multirow[t]{2}{*}{ Test } & \multirow{2}{*}{$\begin{array}{c}\text { Vernik } \\
\text { Türü }\end{array}$} & \multirow{2}{*}{$\begin{array}{l}\text { Yaşlandırma } \\
\text { Süresi }\end{array}$} & \multirow[t]{2}{*}{$\mathbf{N}$} & \multirow[t]{2}{*}{ Ortalama } & \multicolumn{2}{|c|}{$\begin{array}{l}\text { Yaşlandırma } \\
\text { Sonrasi }(\%)\end{array}$} & \multirow[t]{2}{*}{$S S$} & \multirow{2}{*}{$\begin{array}{l}\text { Homo- } \\
\text { jenlik } \\
\text { Grubu }\end{array}$} & \multirow{2}{*}{$\begin{array}{c}\text { Mini } \\
\text {-mum }\end{array}$} & \multirow{2}{*}{$\begin{array}{l}\text { Maksi } \\
\text {-mum }\end{array}$} \\
\hline & & & & & Azalma & Artıs & & & & \\
\hline \multirow{6}{*}{$L^{*}$} & \multirow{3}{*}{$\begin{array}{c}3 \\
\text { Kat }\end{array}$} & Kontrol & 20 & 58.06 & - & - & 1.13 & A & 56.22 & 60.18 \\
\hline & & 252 saat & 20 & 35.61 & 38.67 & - & 0.39 & $\mathrm{C}$ & 35.00 & 36.23 \\
\hline & & 504 saat & 20 & 33.16 & 42.89 & - & 0.42 & $\mathrm{D}^{* * *}$ & 32.48 & 33.84 \\
\hline & \multirow{3}{*}{$\begin{array}{c}5 \\
\text { Kat }\end{array}$} & Kontrol & 20 & 58.13 & - & - & 1.32 & $\mathrm{~A}^{*}$ & 54.70 & 59.95 \\
\hline & & 252 saat & 20 & 39.53 & 32.00 & - & 0.32 & B & 39.07 & 40.16 \\
\hline & & 504 saat & 20 & 35.64 & 38.69 & - & 0.32 & $\mathrm{C}$ & 34.57 & 35.93 \\
\hline \multirow{6}{*}{$a^{*}$} & \multirow{3}{*}{$\begin{array}{c}3 \\
\text { Kat }\end{array}$} & Kontrol & 20 & 12.88 & - & - & 0.65 & $\mathrm{E}^{* * *}$ & 11.28 & 14.01 \\
\hline & & 252 saat & 20 & 29.03 & - & 125.39 & 0.31 & $\mathrm{~A}^{*}$ & 28.59 & 29.70 \\
\hline & & 504 saat & 20 & 26.66 & - & 106.99 & 0.75 & B & 25.83 & 28.73 \\
\hline & \multirow{3}{*}{$\begin{array}{c}5 \\
\text { Kat }\end{array}$} & Kontrol & 20 & 13.07 & - & - & 0.61 & E & 12.17 & 14.06 \\
\hline & & 252 saat & 20 & 24.67 & - & 88.75 & 0.88 & $\mathrm{C}$ & 22.40 & 25.72 \\
\hline & & 504 saat & 20 & 23.66 & - & 81.03 & 0.60 & $\mathrm{D}$ & 22.80 & 25.15 \\
\hline \multirow{6}{*}{$b^{*}$} & \multirow{3}{*}{$\begin{array}{c}3 \\
\text { Kat }\end{array}$} & Kontrol & 20 & 30.72 & - & - & 0.47 & B & 30.03 & 31.70 \\
\hline & & 252 saat & 20 & 18.10 & 41.08 & - & 0.54 & $\mathrm{C}$ & 17.24 & 19.12 \\
\hline & & 504 saat & 20 & 15.64 & 49.09 & - & 0.57 & $\mathrm{D}$ & 14.92 & 16.91 \\
\hline & \multirow{3}{*}{$\begin{array}{c}5 \\
\text { Kat }\end{array}$} & Kontrol & 20 & 31.22 & - & - & 0.23 & $\mathrm{~A}^{*}$ & 30.83 & 31.58 \\
\hline & & 252 saat & 20 & 17.93 & 42.57 & - & 0.56 & $\mathrm{C}$ & 16.99 & 18.74 \\
\hline & & 504 saat & 20 & 13.02 & 58.30 & - & 1.10 & $\mathrm{E}^{* *}$ & 11.61 & 14.97 \\
\hline
\end{tabular}

3 ve 5 kat UV sistem parke verniklerine ait katmanların yaşlandırma sonralarında metot bölümünde verilen renk formülleriyle hesaplanan toplam renk farklarına ait sonuçlar Çizelge 4'de verilmiştir.

Çizelge 4'de verilen sonuçlara göre; her iki vernik için toplam renk farkı değerlerinin arttığ görülmüştür. Yaşlandırma süresinin 252 saatten 504 saate çıktığı uygulamalarda 5 kat uygulamada toplam renk farkı değerleri, 3 kat uygulamaya göre daha az elde edilmiştir. Bunun nedeni olarak; 3 kat uygulamada kullanılan UV perde kaplama yüksek parlaklık kimyasalının, 5 kat uygulamada kullanılan UV şeffaf kürleme sızdırmazlık macunları kimyasallarına göre QUV test cihazında uygulanan yapay yaşlandırmaya karşı daha koyu bir ton oluşturduğu söylenebilir. Payne (1965) tarafından yapılan bir çalışmada hızlandırılmış yaşlandırma uygulanan deney numunelerinde toplam renk değişim değerlerinin yüksek olduğu ve bunun yağmurlamanın, UV ışınlarının ve ısının neden olduğu fotokimyasal 
reaksiyonlar sonucu oluşan serbest radikallerden kaynaklanmış olabileceği şeklinde belirtmiştir.

Çizelge 4. Toplam renk farklılıklarına ait sonuçlar

\begin{tabular}{|c|c|c|c|c|c|c|c|}
\hline $\begin{array}{c}\text { Vernik } \\
\text { Türü }\end{array}$ & $\begin{array}{c}\text { Yaşlandırma } \\
\text { Süresi }\end{array}$ & \multirow{2}{*}{$\boldsymbol{\Delta} \boldsymbol{L}^{*}$} & \multirow{2}{*}{$\boldsymbol{\Delta} \boldsymbol{a}^{*}$} & \multirow{2}{*}{$\boldsymbol{\Delta} \boldsymbol{b}^{*}$} & \multirow{\Delta}{*}{$\boldsymbol{\Delta} \boldsymbol{E}^{*}$} & \multicolumn{2}{|c|}{$\begin{array}{c}\text { 252 Saatlik Yaşlandırma } \\
\text { Sonrası Değişim }\end{array}$} \\
\cline { 5 - 8 } & & & & & Azalma (\%) & Artıs (\%) \\
\hline \multirow{2}{*}{ 3 Kat } & $\mathbf{2 5 2}$ saat & -22.45 & 16.15 & -12.62 & 30.40 & - & - \\
\cline { 2 - 8 } & $\mathbf{5 0 4}$ saat & -24.90 & 13.78 & -15.08 & 32.21 & - & 5.95 \\
\hline \multirow{2}{*}{ 5 Kat } & $\mathbf{2 5 2}$ saat & -18.60 & 11.60 & -13.29 & 25.63 & - & - \\
\cline { 2 - 8 } & $\mathbf{5 0 4}$ saat & -22.49 & 10.59 & -18.20 & 30.81 & - & 20.21 \\
\hline
\end{tabular}

Çizelge 5, yaşlandırılmış ve yaşlandırılmamış UV vernikli malzemelere ait belirlenmiş olan liflere dik ve paralel parlaklık ölçümleri için varyans analizi sonuçlarını göstermektedir. $20^{\circ}, 60^{\circ}$ ve $85^{\circ}$ de liflere dik ve paralel parlaklık değerleri için vernik türü (A), yaşlanma süresi $(\mathrm{B})$ ve bu faktörlerin $(\mathrm{AB})$ etkileşimi anlamlı olarak elde edilmiştir.

Çizelge 5. $20^{\circ}, 60^{\circ}$ ve $85^{\circ}$, de liflere dik $(\perp)$ ve paralel $(/ /)$ parlaklık değerlerine ait varyans analizi sonuçları

\begin{tabular}{|c|c|c|c|c|c|c|}
\hline Test & Varyans Kaynağı & $\begin{array}{l}\text { Kareler } \\
\text { Toplamı }\end{array}$ & $\begin{array}{c}\text { Serbestlik } \\
\text { Derecesi }\end{array}$ & Ortalama Kare & F Değeri & $\alpha \leq 0,05$ \\
\hline \multirow{3}{*}{$/ / 20^{\circ}$} & Vernik Türü (A) & 23.320 & 1 & 23.320 & 1595.253 & $0.000^{*}$ \\
\hline & Yaşlandırma Süresi (B) & 20.308 & 2 & 10.154 & 694.609 & $0.000^{*}$ \\
\hline & Etkileşim (AB) & 13.225 & 2 & 6.613 & 452.346 & $0.000 *$ \\
\hline \multirow{3}{*}{$/ / 60^{\circ}$} & Vernik Türü (A) & 2164.951 & 1 & 2164.951 & 26599.600 & $0.000^{*}$ \\
\hline & Yaşlandırma Süresi (B) & 1582.821 & 2 & 791.411 & 9723.641 & $0.000^{*}$ \\
\hline & Etkileşim (AB) & 603.736 & 2 & 301.868 & 3708.889 & $0.000 *$ \\
\hline \multirow{3}{*}{$/ / \mathbf{8 5}^{\circ}$} & Vernik Türü (A) & 7219.905 & 1 & 7219.905 & 16266.190 & $0.000 *$ \\
\hline & Yaşlandırma Süresi (B) & 3336.734 & 2 & 1668.367 & 3758.772 & $0.000^{*}$ \\
\hline & Etkileşim (AB) & 484.321 & 2 & 242.160 & 545.579 & $0.000^{*}$ \\
\hline \multirow{3}{*}{$\perp 20^{\circ}$} & Vernik Türü (A) & 23.258 & 1 & 23.258 & 12744.027 & $0.000 *$ \\
\hline & Yaşlandırma Süresi (B) & 24.800 & 2 & 12.400 & 6794.352 & $0.000^{*}$ \\
\hline & Etkileşim (AB) & 10.352 & 2 & 5.176 & 2836.128 & $0.000^{*}$ \\
\hline \multirow{3}{*}{$\perp 60^{\circ}$} & Vernik Türü (A) & 1617.736 & 1 & 1617.736 & 85380.529 & $0.000 *$ \\
\hline & Yaşlandırma Süresi (B) & 1233.277 & 2 & 616.639 & 32544.814 & $0.000 *$ \\
\hline & Etkileşim (AB) & 383.118 & 2 & 191.559 & 10110.063 & $0.000^{*}$ \\
\hline \multirow{3}{*}{$\perp \mathbf{8 5}^{\circ}$} & Vernik Türü (A) & 4167.765 & 1 & 4167.765 & 71190.478 & $0.000 *$ \\
\hline & Yaşlandırma Süresi (B) & 887.387 & 2 & 443.694 & 7578.824 & $0.000 *$ \\
\hline & Etkileşim (AB) & 286.620 & 2 & 143.310 & 2447.910 & $0.000^{*}$ \\
\hline \multicolumn{7}{|c|}{ *: Anlamlı } \\
\hline
\end{tabular}

Çizelge 6, UV sistem parke verniği uygulanan test numunelerinin yaşlandırma uygulamalarından önce ve sonralarında belirlenmiş olan parlaklık ölçümlerine ait istatistiksel sonuçlarını göstermektedir. $\mathrm{Bu}$ sonuçlara göre, yaşlandırma sonrasında tüm parlaklık değerlerinin (liflere dik ve paralel yönleri ve $20^{\circ}, 60^{\circ}$ ve $85^{\circ}$ derecelerinin) azaldığ belirlenmiştir. Ayrıca 5 kat uygulamadaki parlaklık değerlerinin 3 kat uygulamadaki parlaklık değerlerinden daha yüksek olduğu görülmektedir. Parlaklıktaki bu artışın 5 kat uygulamasında kullanılan UV şeffaf kürleşen sızdırmazlık macunlarından (T9110-0000H T9110-0000) kaynaklandığı söylenebilir.

Gürleyen (2020) ve (2021) tarafindan yapılan UV sistem vernikli çalışmalarda varılan sonuçların çalışmamızla benzerlik gösterdiği belirlenmiştir. 
Çizelge 6. $20^{\circ}, 60^{\circ}$ ve $85^{\circ}$ de liflere dik $(\perp)$ ve paralel $(/ /)$ parlaklık değerleri sonuçları

\begin{tabular}{|c|c|c|c|c|c|c|c|c|c|c|}
\hline \multirow[t]{2}{*}{ Test } & \multirow{2}{*}{$\begin{array}{c}\text { Vernik } \\
\text { Türü }\end{array}$} & \multirow{2}{*}{$\begin{array}{l}\text { Yaşlandırma } \\
\text { Süresi }\end{array}$} & \multirow[t]{2}{*}{$\mathbf{N}$} & \multirow[t]{2}{*}{ Ortalama } & \multicolumn{2}{|c|}{$\begin{array}{l}\text { Yaşlandırma } \\
\text { Sonrası (\%) }\end{array}$} & \multirow[t]{2}{*}{$S S$} & \multirow{2}{*}{$\begin{array}{c}\text { Homojenlik } \\
\text { Grubu }\end{array}$} & \multirow{2}{*}{$\begin{array}{l}\text { Mini } \\
\text {-mum }\end{array}$} & \multirow{2}{*}{$\begin{array}{l}\text { Maksi } \\
\text {-mum }\end{array}$} \\
\hline & & & & & Azalma & Artış & & & & \\
\hline \multirow{6}{*}{$/ / 20^{\circ}$} & \multirow{3}{*}{$\begin{array}{c}3 \\
\text { Kat }\end{array}$} & Kontrol & 20 & 0.43 & - & - & 0.05 & $\mathrm{C}$ & 0.40 & 0.50 \\
\hline & & 252 saat & 20 & 0.14 & 67.44 & - & 0.05 & $\mathrm{E}^{* * *}$ & 0.10 & 0.20 \\
\hline & & 504 saat & 20 & 0.26 & 39.53 & - & 0.26 & $\mathrm{D}$ & 0.10 & 0.80 \\
\hline & \multirow{3}{*}{$\begin{array}{c}5 \\
\text { Kat }\end{array}$} & Kontrol & 20 & 2.11 & - & - & 0.11 & $\mathrm{~A}^{*}$ & 1.80 & 2.20 \\
\hline & & 252 saat & 20 & 1.06 & 49.76 & - & 0.07 & $\mathrm{~B}$ & 0.90 & 1.10 \\
\hline & & 504 saat & 20 & 0.31 & 85.31 & - & 0.02 & D & 0.30 & 0.40 \\
\hline \multirow{6}{*}{$/ / 60^{\circ}$} & \multirow{3}{*}{$\begin{array}{c}3 \\
\text { Kat }\end{array}$} & Kontrol & 20 & 4.26 & - & - & 0.20 & $\mathrm{C}$ & 4.00 & 4.50 \\
\hline & & 252 saat & 20 & 1.76 & 58.69 & - & 0.21 & $\mathrm{E}$ & 1.30 & 2.00 \\
\hline & & 504 saat & 20 & 0.86 & 79.81 & - & 0.06 & $\mathrm{~F}$ & 0.80 & 1.00 \\
\hline & \multirow{3}{*}{$\begin{array}{c}5 \\
\text { Kat }\end{array}$} & Kontrol & 20 & 17.99 & - & - & 0.17 & $\mathrm{~A}^{*}$ & 17.70 & 18.20 \\
\hline & & 252 saat & 20 & 10.75 & 40.24 & - & 0.08 & B & 10.60 & 10.90 \\
\hline & & 504 saat & 20 & 3.63 & 79.82 & - & 0.61 & $\mathrm{D}$ & 3.10 & 6.10 \\
\hline \multirow{6}{*}{$/ / 8^{\circ}$} & \multirow{3}{*}{$\begin{array}{c}3 \\
\text { Kat }\end{array}$} & Kontrol & 20 & 9.33 & - & - & 0.33 & D & 8.60 & 9.50 \\
\hline & & 252 saat & 20 & 1.83 & 80.39 & - & 0.40 & $\mathrm{E}$ & 0.80 & 2.30 \\
\hline & & 504 saat & 20 & 0.37 & 96.03 & - & 0.19 & $\mathrm{~F}^{* *}$ & 0.20 & 0.70 \\
\hline & \multirow{3}{*}{$\begin{array}{c}5 \\
\text { Kat }\end{array}$} & Kontrol & 20 & 27.09 & - & - & 0.28 & $\mathrm{~A}^{*}$ & 26.50 & 27.30 \\
\hline & & 252 saat & 20 & 20.74 & 23.44 & - & 0.45 & B & 20.10 & 21.50 \\
\hline & & 504 saat & 20 & 10.24 & 62.20 & - & 1.44 & $\mathrm{C}$ & 8.40 & 13.60 \\
\hline \multirow{6}{*}{$\perp 20^{\circ}$} & \multirow{3}{*}{$\begin{array}{c}3 \\
\text { Kat }\end{array}$} & Kontrol & 20 & 0.50 & - & - & 0.00 & $\mathrm{C}$ & 0.50 & 0.50 \\
\hline & & 252 saat & 20 & 0.10 & 80.00 & - & 0.00 & $\mathrm{~F}^{* *}$ & 0.10 & 0.10 \\
\hline & & 504 saat & 20 & 0.13 & 74.00 & - & 0.05 & $\mathrm{E}$ & 0.10 & 0.20 \\
\hline & \multirow{3}{*}{$\begin{array}{c}5 \\
\text { Kat }\end{array}$} & Kontrol & 20 & 2.09 & - & - & 0.06 & $\mathrm{~A}^{*}$ & 2.00 & 2.20 \\
\hline & & 252 saat & 20 & 1.00 & 52.15 & - & 0.06 & B & 0.90 & 1.10 \\
\hline & & 504 saat & 20 & 0.28 & 86.60 & - & 0.04 & $\mathrm{D}$ & 0.20 & 0.30 \\
\hline \multirow{6}{*}{$\perp 6^{\circ}$} & \multirow{3}{*}{$\begin{array}{c}3 \\
\text { Kat }\end{array}$} & Kontrol & 20 & 4.19 & - & - & 0.07 & $\mathrm{C}$ & 4.00 & 4.30 \\
\hline & & 252 saat & 20 & 1.23 & 70.64 & - & 0.14 & E & 1.00 & 1.50 \\
\hline & & 504 saat & 20 & 0.70 & 83.29 & - & 0.00 & $\mathrm{~F}^{* * *}$ & 0.70 & 0.70 \\
\hline & \multirow{3}{*}{$\begin{array}{c}5 \\
\text { Kat }\end{array}$} & Kontrol & 20 & 15.49 & - & - & 0.06 & $\mathrm{~A}^{*}$ & 15.40 & 15.60 \\
\hline & & 252 saat & 20 & 9.31 & 39.90 & - & 0.25 & $\mathrm{~B}$ & 9.00 & 10.20 \\
\hline & & 504 saat & 20 & 3.35 & 78.37 & - & 0.14 & $\mathrm{D}$ & 3.10 & 3.60 \\
\hline & & Kontrol & 20 & 2.87 & - & - & 0.24 & $\mathrm{D}$ & 2.60 & 3.20 \\
\hline & Kat & 252 saat & 20 & 0.54 & 81.18 & - & 0.13 & E & 0.30 & 0.70 \\
\hline 18 & & 504 saat & 20 & 0.17 & 94.08 & - & 0.10 & $\mathrm{~F}^{* * *}$ & 0.10 & 0.30 \\
\hline $\mathbf{L} \mathbf{3}$ & & Kontrol & 20 & 18.73 & - & - & 0.26 & $\mathrm{~A}^{*}$ & 18.40 & 19.20 \\
\hline & Kat & 252 saat & 20 & 11.65 & 37.80 & - & 0.17 & $\mathrm{~B}$ & 11.30 & 12.10 \\
\hline & & 504 saat & 20 & 8.56 & 54.30 & - & 0.41 & $\mathrm{C}$ & 7.90 & 9.30 \\
\hline
\end{tabular}

Salınımsal sertlik değeri için varyans analizi sonuçları Çizelge 7'de gösterilmektedir. Salınımsal sertlik değerinde vernik türü (A), yaşlandırma süresi (B) ve etkileşim (AB) anlamlı olarak elde edilmiştir.

Çizelge 7. Salınımsal sertlik değeri için varyans analizi sonuçları

\begin{tabular}{|c|c|c|c|c|c|}
\hline Varyans Kaynă̆ı & $\begin{array}{c}\text { Kareler } \\
\text { Toplamı }\end{array}$ & $\begin{array}{c}\text { Serbestlik } \\
\text { Derecesi }\end{array}$ & Ortalama Kare & F Değeri & $\boldsymbol{\alpha} \leq \mathbf{0 , 0 5}$ \\
\hline Vernik Türü (A) & 25585.350 & 1 & 25585.350 & 609.955 & $0.000^{*}$ \\
\hline Yaşlandırma Süresi (B) & 346.900 & 2 & 173.450 & 4.135 & $0.021^{*}$ \\
\hline Etkileşim (AB) & 5944.300 & 2 & 2972.150 & 70.856 & $0.000^{*}$ \\
\hline \multicolumn{7}{|c|}{ *: Anlamlı } \\
\hline
\end{tabular}


Çizelge 8'de, König metoduna göre belirlenmiş olan salınımsal sertlik değerleri için SPSS sonuçları verilmiştir. Verilen bu sonuçlara göre, 3 kat vernikli katmanlarda yaşlandırma sonrasında salınımsal sertlik değerleri azalırken, 5 kat uygulanmış UV sistem vernikli katmanlarda zit bir durum görülmektedir. Buna ek olarak, 5 kat uygulanmış deney örneklerinin salınımsal sertlik değerleri 3 kat uygulanmış test örneklerininkinden fazla olduğu görülmüştür.

Gürleyen (2020) ve (2021) tarafindan yapılan çalışmalarda da benzer sonuçlar elde edilmiştir. Holzhausen ve ark., (2002) tarafından yapılan bir araştırmada, fiziksel ve kimyasal yaşlandırmanın organik vernik/boya sistemlerinin yapısında iç gerilim oluşturduğu ve kırılganlığın artmasına sebep olduğu belirtilerek katmanın çatlamaya karşı direncinin en yüksek olduğu sicaklık derecelerinin $25^{\circ} \mathrm{C}, 40^{\circ} \mathrm{C}$ ve $60^{\circ} \mathrm{C}$ olduğunu söylemişlerdir.

Çizelge 8. Salınımsal sertlik değerlerine ait sonuçlar

\begin{tabular}{|c|c|c|c|c|c|c|c|c|c|}
\hline \multirow{2}{*}{$\begin{array}{c}\text { Vernik } \\
\text { Türü }\end{array}$} & \multirow{2}{*}{$\begin{array}{l}\text { Yaşlandırma } \\
\text { Süresi }\end{array}$} & \multirow[t]{2}{*}{$\mathbf{N}$} & \multirow[t]{2}{*}{ Ortalama } & \multicolumn{2}{|c|}{$\begin{array}{r}\text { Yaşlandırma } \\
\text { Sonrası (\%) }\end{array}$} & \multirow[t]{2}{*}{$S S$} & \multirow{2}{*}{$\begin{array}{c}\text { Homojenlik } \\
\text { Grubu }\end{array}$} & \multirow{2}{*}{$\begin{array}{c}\text { Mini } \\
\text {-mum }\end{array}$} & \multirow{2}{*}{$\begin{array}{l}\text { Maksi } \\
\text {-mum }\end{array}$} \\
\hline & & & & Azalma & Artış & & & & \\
\hline \multirow{3}{*}{$\begin{array}{c}3 \\
\text { Kat }\end{array}$} & Kontrol & 10 & 79.80 & - & - & 7.63 & $\mathrm{C}$ & 67.00 & 92.00 \\
\hline & 252 saat & 10 & 67.20 & 15.79 & - & 3.91 & $\mathrm{D}$ & 62.00 & 76.00 \\
\hline & 504 saat & 10 & 61.50 & 22.19 & - & 4.09 & $\mathrm{D}^{* * *}$ & 56.00 & 68.00 \\
\hline \multirow{3}{*}{$\begin{array}{c}5 \\
\text { Kat }\end{array}$} & Kontrol & 10 & 93.70 & - & - & 6.07 & B & 85.00 & 104.00 \\
\hline & 252 saat & 10 & 116.60 & - & 24.44 & 7.85 & A & 105.00 & 129.00 \\
\hline & 504 saat & 10 & 122.10 & - & 30.31 & 7.94 & $\mathrm{~A}^{*}$ & 110.00 & 133.00 \\
\hline
\end{tabular}

Çizelge 9'da yüzeye yapışma direnci için varyans analizi sonuçları gösterilmektedir. Yüzeye yapışma direnci için vernik türü $(A)$, yaşlandırma süresi $(B)$ ve etkileşim (AB) anlamlı olarak elde edildiği görülmektedir.

Çizelge 9. Yüzeye yapışma direnci için varyans analizi sonuçları

\begin{tabular}{|c|c|c|c|c|c|}
\hline Varyans Kaynağı & Kareler Toplamı & $\begin{array}{c}\text { Serbestlik } \\
\text { Derecesi }\end{array}$ & Ortalama Kare & F Değeri & $\mathbf{\alpha} \leq \mathbf{0 , 0 5}$ \\
\hline Vernik Türü (A) & 17.343 & 1 & 17.343 & 131.438 & $0.000^{*}$ \\
\hline Yaşlandırma Süresi (B) & 6.256 & 2 & 3.128 & 23.706 & $0.000^{*}$ \\
\hline Etkileșim (AB) & 7.961 & 2 & 3.981 & 30.167 & $0.000^{*}$ \\
\hline \multicolumn{7}{|r}{} & *: Anlamlı \\
\hline
\end{tabular}

Çizelge 10'da yüzeye yapışma direnci için belirlenmiş olan SPSS sonuçları gösterilmektedir.

Çizelge 10. Yüzeye yapışma direncine ait sonuçları

\begin{tabular}{|c|c|c|c|c|c|c|c|c|c|}
\hline \multirow{2}{*}{$\begin{array}{l}\text { Vernik } \\
\text { Türü }\end{array}$} & \multirow{2}{*}{$\begin{array}{l}\text { Yaşlandırma } \\
\text { Süresi }\end{array}$} & \multirow[t]{2}{*}{$\mathbf{N}$} & \multirow{2}{*}{$\begin{array}{c}\text { Ortalama } \\
\text { (MPa) }\end{array}$} & \multicolumn{2}{|c|}{$\begin{array}{l}\text { Yaşlandırma } \\
\text { Sonrası (\%) }\end{array}$} & \multirow[t]{2}{*}{$S S$} & \multirow{2}{*}{$\begin{array}{c}\text { Homojenlik } \\
\text { Grubu }\end{array}$} & \multirow{2}{*}{$\begin{array}{l}\text { Mini } \\
\text {-mum }\end{array}$} & \multirow{2}{*}{$\begin{array}{l}\text { Maksi } \\
\text {-mum }\end{array}$} \\
\hline & & & & Azalma & Artış & & & & \\
\hline \multirow{3}{*}{$\begin{array}{c}3 \\
\text { Kat }\end{array}$} & Kontrol & 5 & 2.540 & - & - & 0.14 & $\mathrm{C}$ & 2.330 & 2.680 \\
\hline & 252 saat & 5 & 3.458 & - & 36.14 & 0.36 & B & 3.080 & 3.930 \\
\hline & 504 saat & 5 & 4.840 & - & 30.31 & 0.71 & $\mathrm{~A}^{*}$ & 3.640 & 5.370 \\
\hline \multirow{3}{*}{$\begin{array}{c}5 \\
\text { Kat }\end{array}$} & Kontrol & 5 & 2.350 & - & - & 0.27 & $\mathrm{C}$ & 2.130 & 2.790 \\
\hline & 252 saat & 5 & 1.786 & 24.00 & - & 0.19 & $\mathrm{D}^{* *}$ & $\begin{array}{l}1.590 \\
\end{array}$ & 2.030 \\
\hline & 504 saat & 5 & 2.140 & 8.94 & - & 0.20 & CD & 1.860 & 2.370 \\
\hline
\end{tabular}


Çizelge 10 incelendiğinde, 3 kat uygulamasına sahip vernikli katmanlarda 252 ve 504 saatlik yaşlandırma sonrasında yapışma artarken, 5 kat uygulanmış UV sistem vernikli katmanlarda 252 saatlik uygulama sonunda önce bir azalış 504 saatlik uygulama sonunda ise artış olduğu görülmüştür. Clerc ve ark., (2017) hava koşullarına bağlı yapışma mukavemeti kaybı, çoğu zaman yapıştırıcının kimyasal olarak bozulmasından ziyade ahşabın bozulmasından kaynaklanmaktadır. Bu duruma göre, 5 kat UV vernik uygulanmış örnekler için yapışma mukavemetinde azalma vardır.

\section{Sonuçlar ve Öneriler}

$\mathrm{Bu}$ çalışmada, 3 ve 5 katlı UV sistem vernik uygulanmış kayısı odunu parkelerinin yüzeylerinde yapılan yaşlandırma uygulamalarından sonra aşağıdaki sonuçlar elde edilmiştir:

- Elde edilen istatistiksel sonuçlar, çalışmada kullanılan kimyasalların yapısal özelliklerinin tamamen farklı olduğunu ve ayrıca ahşap ile yaşlanma arasındaki etkileşim seviyesini hangi zamanda etkilediğini göstermektedir.

- Tüm testlere ait varyans analizi sonuçlarının anlamlı olduğu sonucuna varılmıştır.

- Salınımsal sertlik değerinin 5 kat vernik uygulamasında, 3 kat uygulamasından büyük olduğu belirlenirken, yüzeye yapışma direnci için zit bir durumun olduğu sonucuna ulaşılmıştır. Ayrıca yaşlandırma sonrasında 3 kat vernik uygulamasına sahip örneklerin sertlik değeri azalırken, 5 kat uygulamasına sahip örneklerin sertlik değerinin arttığ belirlenmiştir.

- Her iki vernik uygulamasında bütün parlaklık değerleri, $L^{*}$ ve $b^{*}$ tonu değerleri azalırken, $a^{*}$ tonu değerleri artmıştır.

- Çalışmada kullanılan kimyasalların farklı testler üzerinde farklı sonuçlar verdiği sonucuna ulaşılmıştır. Kayısı odununun UV sistem parke üretiminde kullanılabileceği söylenebilir.

\section{Teşekkür}

Yazarlar, UV sistem parke verniği uygulamaları için KPS Fabrikası'na (Düzce) teşekkür etmektedir.

\section{Kaynaklar}

Anonim, (2002), Consensus document on the biology of Prunus sp. (stone fruits): series on harmonization of regulatory oversights in biotechnology nr. 24. http://www.olis.oecd.org/olis/2002doc.nsf/LinkTo/env-jm-mono.

ASTM D 2244-3, (2007), Standard practice for calculation or color tolerances and color, differences from instrumentally measured color coordinates, ASTM International, West Conshohocken, PA.

ASTM D 4366-95, (1984), Standard test methods for hardness of organic coatings by pendulum test, ASTM, Philadelphia, PA.

ASTM D 4541, (1995), Standard test method for pull-off strength of coatings using portable adhesion testers, ASTM International, West Conshohocken, PA.

Ayata, Ü., (2019), Effects of artificial weathering on the surface properties of ultraviolet varnish applied to lemonwood (Citrus limon (L.) Burm.), Bioresources, 14(4), 83138323. DOI: 10.15376/biores.14.4.8313-8323. 
Ayata, Ü., Bal, B.C., (2019), Kayısı (Prunus armeniaca L.) odununda çivi tutma direnci ve janka sertlik değerinin belirlenmesi, Ziraat, Orman ve Su Ürünleri Alanında Yeni Ufuklar, Gece Kitaplığı Yayınevi, Ankara, Türkiye, Genel Yayın Yönetmeni: Atilla Atik, Editörler: Ali Musa Bozdoğan ve Nigar Yarpuz-Bozdoğan, Birinci Basım, 16 Ekim 2019, 368-376. ISBN: 978-605-7749-52-9.

Ayata, Ü., Cavus, V., (2018), The determination of the surface adhesion resistance and pendulum hardness on the parquets applied UV varnish as single and double layers, Journal of Engineering Sciences and Design, 6(4), 541-545. DOI: $10.21923 /$ jesd. 388346 .

Ayata, Ü., Gurleyen, L., Esteves, B., Gurleyen, T., Cakicier, N., (2017a), Effect of heat treatment (ThermoWood) on some surface properties of parquet beech (Fagus orientalis Lipsky.) with different layers of UV system applied, BioResources, 12(2), :3876-3889. DOI: $10.15376 /$ biores. 12.2.3876-3889.

Ayata, Ü., Gürleyen, T., Gürleyen, L., Esteves, B., Çakıcıer, N., (2017b), 212 ${ }^{\circ} \mathrm{C}$ 'de 2 saat süreyle 1sıl işlem görmüş (ThermoWood) ve tek/çift kat UV sistem parke vernik uygulanmış dişbudak (Fraxinus excelsior) odununda bazı yüzey özelliklerinin belirlenmesi, 5. Uluslararası Mühendislik Ve Bilim Alanında Yenilikçi Teknolojiler Sempozyumu, Mimarlık ve İnşaat Üniversitesi, 29 Eylül - 01 Ekim, Bakü, Azerbaycan, 1318-1326.

Ayata, Ü., Şahin, S., Gürleyen, L., Esteves, B., (2018), UV sistem vernik uygulanmış lamine parkelerde yüzeye yapışma direnci üzerine termal yaşlandırmanın etkisi, Multidisipliner Çalışmalar-3 (Sağlık ve Fen Bilimleri), Gece Kitaplığı Yayınevi, Birinci Basım, Ocak 2018, Editörler: Rıdvan KARAPINAR, Murat A. KUŞ, Ankara, Türkiye, 301-311. ISBN: 978-605-288-223-8.

Baytop, T., (1999), Türkiye'de bitkilerle tedavi, İstanbul: İstanbul Eczacılık Fakültesi Yayınları.

Clerc, G., Brülisauer, M., Affolter, S., Volkmer, T., Pichelin, F., Niemz, P., (2017), Characterization of the ageing process of one-component polyurethane moisture curing wood adhesive, International Journal of Adhesion and Adhesives, 72, 130-138. DOI: 10.1016/j.ijadhadh.2016.09.008.

Çavuş, V., (2020), Kayısı ağacı (Prunus armeniaca L.) odununun bazı fiziksel ve mekanik özelliklerinin belirlenmesi, Bartın Orman Fakültesi Dergisi, 22(2), 457-464. DOI: 10.24011/barofd.729707.

Gençer, A., Özgül, U., Onat, S.M., Gündüz, G., Yaman, B., Yazıcı, H., (2018), Kayısı (Prunus armeniaca L.) odunu ve meyve endokarpının kimyasal ve morfolojik özellikleri, Bartın Orman Fakültesi Dergisi, 20(2), 205-209. DOI: 10.24011/barofd.412958.

Gurleyen, L., (2021), Effects of artificial weathering on the color, gloss, adhesion, and pendulum hardness of UV system parquet varnish applied to doussie (Afzelia africana) wood,. BioResources, 16(1), 1616-1627. DOI: 10.15376/biores.16.1.1616-1627.

Gurleyen, L., Ayata, U., Esteves, B., Cakicier, N., (2017a), Effects of heat treatment on the adhesion strength, pendulum hardness, surface roughness, color and glossiness of scots pine laminated parquet with two different types of UV varnish application, MaderasCiencia y Tecnologia 19(2), 213-224. DOI: 10.4067/S0718-221X2017005000019. 
Gurleyen, L., Ayata, U., Esteves, B., Gurleyen, T., Cakicier, N., (2019), Effects of thermal modification of oak wood upon selected properties of coating systems, Bioresources, 14(1), 1838-1849. DOI: 10.15376/biores.14.1.1838-1849.

Gürleyen, L., (2020), UV sistem parke verniği uygulanmış gülibrişim (Albizia julibrissin) odununda bazı yüzey özellikleri üzerine yapay yaşlandırmanın etkisi, Türkiye Ormancllık Dergisi, 21(4), 451-460. DOI: 10.18182/tjf.795597.

Gürleyen, T., Ayata, Ü., Gürleyen, L., Esteves, B., Çakıcıer, N., (2017b), Üvez (Sorbus L.) odununa uygulanan tek ve çift kat UV Sistem parke vernik katmanlarında renk, parlaklık ve salınımsal sertlik değerlerinin belirlenmesi, 5. Uluslararası Mühendislik Ve Bilim Alanında Yenilikçi Teknolojiler Sempozyumu, Mimarlık ve İnşaat Üniversitesi, 29 Eylül - 01 Ekim, Bakü, Azerbaycan, 1327-1336.

Gürleyen, T., Ayata, Ü., Gürleyen, L., Esteves, B., Sivrikaya, H., Can, A., (2017c), Tek ve çift kat UV vernik sistemi uygulanmış parkelerde renk ve parlaklık değerlerinin belirlenmesi, 2. Uluslararası Malzeme Bilimi ve Teknolojisi Konferansı Kapadokya (IMSTEC 2017), 11-13 Ekim, Nevşehir, Türkiye, 408-412.

Holzhausen U., Millow S., Adler H.J.P., (2002), Studies on the thermal ageing of organic coatings, Wiley-WCH Verlag GmbH, Weinheim, 187(1), 939-952. DOI: 10.1002/15213900(200209)187:1<939:AID-MASY939>3.0.CO;2-E.

ISO 2813, (1994), Paints and varnishes - determination of specular gloss of non-metallic paint films at 20 degrees, 60 degrees and 85 degrees, International Organization for Standardization, Geneva, Switzerland.

ISO 4892-3, (2016), Plastics - Methods of exposure to laboratory light sources - Part 3: Fluorescent UV lamps, The International Organization for Standardization.

Kipphan, H., (2001), Handbook of Print Media: Technologies and Production Methods, Springer, Berlin, Heidelberg.

Payne, H.F., (1965), Organic coating technology, volume I, printed in New York U.S.A. Fourth Printing.

Salca, E.A., Krystofiak, T., Lis, B., Mazela, B., Proszyk, S., (2016), Some coating properties of black alder wood as a function of varnish type and application method, BioResources, 11(3), 7580-7594. DOI: 10.15376/biores.11.3.7580-7594.

Söğütlü, C., Sönmez, A., (2006), Değişik koruyucular ile işlem görmüş bazı yerli ağaçlarda UV ışınlarının renk değiştirici etkisi, Gazi Üniversitesi Mühendislik Mimarlık Fakültesi Dergisi, 21(1), 151-159.

TS 2471 (1976), Odunda fiziksel ve mekaniksel deneyler için rutubet miktarı tayini, Türk Standartları Enstitüsü, Ankara.

URL 1. Kayısı (Prunus armeniaca L.) ağacı hakkında bazı bilgiler, https://www.wooddatabase.com/apricot/, (21.03.2021).

Vardanyan, V., Poaty, B., Chauve, G., Landry, V., Galstıan, T., Riedl, B., (2014), Mechanical properties of UV-waterborne varnishes reinforced by cellulose nanocrystals, Journal of Coatings Technology and Research, 11(6), 841-852. DOI: 10.1007/s11998-014-9598-3. 